\title{
ABRINDO AS PORTAS PARA AS ATIVIDADES CIRCENSES NA EDUCAÇÃO FÍSICA ESCOLAR: UM RELATO DE EXPERIÊNCIA
}

\section{Flora Sumie Takamori}

Prefeitura Municipal de Guarulhos, Guarulhos, São Paulo, Brasil

\section{Marco Antonio Coelho Bortoleto}

Universidade Estadual de Campinas, Campinas, São Paulo, Brasil

\section{Maikon Oliveira Liporoni}

Instituto Oripaba, Mauá, São Paulo, Brasil

\section{Mario Johannes Henricus Palmen}

Universidade Estadual de Campinas, Campinas, São Paulo, Brasil

\section{Thais Di Cavallotti}

Centro Universitário Herminio Ometto, Araras, São Paulo, Brasil

\section{Resumo}

Este artigo relata a experiência do desenvolvimento de atividades circenses em aulas extracurriculares de Educação Física, num projeto social patrocinado pela lei de incentivo fiscal na cidade de Mauá (SP), durante o ano de 2006. Nele descrevemos a importância deste tipo de atividade para as aulas de Educação Física, assim como as modalidades circenses abordadas, o processo pedagógico empregado e outros aspectos que permearam o referido projeto.

Palabras-chave: Atividades Circenses - Educação Física Escolar - Circo

\section{Introdução}

$\neg$ ste artigo relata a experiência de um professor de Educação FísiLca com as atividades circenses em aulas extraescolares para crianças de baixa renda, na cidade de Mauá (SP), realizada entre 24/03 e 7/12/2006, como parte de um projeto financiado pela Petrobrás denominado "Programa de Criança".

A metodologia aplicada na construção deste artigo foi baseado em estudo exploratório, segundo Dencker (1998), utilizamos fontes secundárias e observação informal. $\mathrm{O}$ artigo foi composto de entrevistas com o professor em questão e posteriormente avaliado e organizado em forma de relato de experiência. Nele, abordamos a organização do projeto, o processo de ensino-aprendizagem, a metodologia das aulas, 
a interação das idades com as modalidades aplicadas, a diversidade do espaço utilizado e as relações estabelecidas entre os participantes (educadores e educandos) e as atividades circenses.

Para contextualizar o ensino das modalidades circenses nas aulas de Educação Física, buscamos, em Silva (1996, p. 12), a linha histórica do circo e percebemos que o processo de ensino-aprendizagem prosseguiu "através da transmissão da arte do pai para o filho" (oralidade) independente do formato de circo vigente ("circo família", "circo tradicional", "novo circo", "circo moderno" e "circo teatro"), porém, a partir de 1940 a 1950, inicia-se uma ruptura na forma da transmissão deste saber circense, com o surgimento das escolas de circo. Dentro dessa lógica, os elementos circenses saem das lonas e começam a ser trabalhado em diferentes espaços, evento, projetos social e, inclusive, no âmbito escolar, dentro da disciplina de Educação Física (SILVA, 1996, p. 13).

Considerando os conteúdos dessa disciplina, observamos que as atividades circenses pertencem ao grupo de atividades expressivas e devem, portanto, ser tratadas nas aulas seguindo a determinação dos Parâmetros Curriculares Nacionais (PCNs) (BRASIL, 1997) ao mesmo tempo que os princípios que norteiam a Educação Física no Ensino Fundamental: Princípio da Diversidade, Princípio da Inclusão e Categorias de Conteúdos (BORTOLETO; MACHADO, 2003). Dessa maneira, por tratar de uma manifestação da cultura corporal, a arte circense pode ser vista como uma forma organizada, multifacetada, interrelacionada de Educar o físico, legitimado pela Lei de Diretrizes e Bases (LDB) (BRASIL, 1996).

Além do caráter postulado pela legislação, outro fator importante e que torna o Circo parte necessária dos conteúdos obrigatórios no currículo escolar é o fato de ser considerado como patrimônio cultural que, com as referências culturais e preservação da identidade de um povo, resiste aos movimentos globalizadores, os quais descaracterizam identidades, impossibilitando as gerações seguintes de conhecer esta forma de expressão artística. A cultura circense une histórica e geograficamente um povo, e, dentro desta perspectiva, facilita o processo de ensino e aprendizagem pela reflexão sobre a identidade social de um grupo, intermediando as relações contextualizadoras com a realidade e propondo medidas de sustentabilidade.

Assim, a inserção das atividades circenses na escola oportuniza a desmistificação de alguns equívocos próprios ao senso comum acerca 
desse tipo de atividade, como, por exemplo, o de que é prática pouco séria, enganosa, pouco organizada, realizada por pessoas que não merecem respeito (BORTOLETO, 2003, p. 27).

Além disso, se, de acordo com Schawrzt (2002), a criança é automotiva para qualquer prática, principalmente a lúdica e não se importa se está indo bem ou mal em uma atividade, o que lhe interessa é saber se está ou não tendo prazer nisso; e, se a arte circense contempla esses princípios, ela é adequada aos objetivos da Educação Física Escolar.

Diante disso, importa muito o fato de que a característica das aulas de atividades circenses ministradas pelo referido educador foi a ludicidade, buscando "romper a institucionalização da ordem disciplinada típica da organização social escolar", sendo "um lugar de construção e re-construção de saberes e práticas, e de constituição de singularidades, escapando dos enquadramentos tradicionais, mantendo o componente educativo, oferecendo a oportunidade para novas descobertas" (SOARES, p. 64, 2002).

A introdução dos elementos circenses nessas aulas surgiu da curiosidade dos educandos sobre o circo. Para satisfazê-la, o educador organizou as aulas em quatro momentos. Os encontros aconteceram tanto com os educandos iniciantes (6 a 10 anos), como com os intermediários (11 a 15 anos), duas vezes por semana, em dias alternados, com 1 hora e 10 minutos por aula. Um dos resultados dessa iniciativa foi a elaboração de um espetáculo circense criado e apresentado pelos educandos como forma de avaliação ao final do projeto, além disso, o projeto financiado pela Petrobrás - Programa de Criança, deu continuidade a outros projetos similares na comunidade do Jardim Oratória ${ }^{1}$ em Mauá.

Assim, ao longo deste artigo, analisamos detalhadamente essa experiência prática com o objetivo de sistematizar o método empregado, e de que estas anotações possam servir como um ponto de partida para outros professores ou profissionais que desejem inserir atividades circenses em aulas de Educação Física e/ou em seu campo de atuação.

\section{As atividades circenses nas aulas de Educação Física}

Somos conscientes da possibilidade de aplicar as atividades circen-

1-Instituto Oripaba - Jarim Itaussu, Chacará das Flores - Euripedes BarzanulfoAssociação Amigos do Jardim Oratório II. http://institutooripaba.spaces.live.com/ 
ses em diferentes ambientes (escolas, clubes, academias, etc.), com distintas faixas etárias e condições sócio-econômicas. Apresentamos, então, a experiência de um educador que encontrou espaço para esse tipo de atividade em suas aulas extraescolares de Educação Física.

O interesse do professor pelo circo surgiu, a priori, de forma desinteressada. Durante vários meses experimentou diversas modalidades circenses, como os malabares e equilíbrio sobre objetos (rola bola), incorporando esse conhecimento na educação não-formal, a partir de suas aulas de Educação Física. Tal decisão, também, tem sido tomada por outros profissionais sensibilizados com esta prática, como podemos observar nesta passagem:

No Brasil, a inclusão das atividades físicas circenses também começa a dar seus primeiros passos. Há notícias da existência de escolas públicas e privadas em algumas regiões (São Paulo, Bahia, Rio de Janeiro, etc.) que já incluem as atividades circenses como conteúdo da Educação Física em diferentes níveis, graças principalmente à ação de profissionais que se sentem sensibilizados com esta questão por já terem vivido algum tipo de experiência nesta área. (BORTOLETO ; MACHADO, 2003, p. 45)

A ideia de utilizar as atividades circenses foi motivada pela curiosidade dos próprios alunos, quando tiveram contato casual com parte de seu material didático, no caso, um "bastão chinês". Depois de uma breve demonstração, o educador sentiu que poderia abordar tal conteúdo, sobretudo pela grande receptividade demonstrada pelos educandos.

Durante o primeiro semestre, esse educador anunciou paulatinamente diferentes materiais e modalidades circenses que seriam propostos posteriormente, criando uma grande expectativa, diminuindo a evasão e a baixa frequência ocasionada pela falta de interesse nas atividades esportivas. A novidade deste conteúdo gerou uma transformação para o projeto pedagógico do professor. $\mathrm{O}$ contato definitivo entre os alunos e as atividades circenses ocorreu no segundo semestre de 2006.

Nessa experiência, as atividades circenses foram trabalhadas com o objetivo de proporcionar diversidade cultural, inclusão, autonomia, criatividade, expressão corporal, sociabilidade de forma lúdica, e o fe- 
chamento do trabalho deu-se com a apresentação de um espetáculo circense elaborado pelas próprias crianças. Dessa forma, abandonouse ali os moldes convencionais para as aulas de Educação Física.

Descrição do projeto

Segundo a página eletrônica oficial da empresa patrocinadora, o macro-projeto, denominado o "Programa de Criança" tem uma gama de responsabilidades sociais desenvolvidas e aplicadas dentro do macro projeto denominado "O Programa de Criança":

Objetiva melhorar a qualidade de vida das crianças. É um projeto de longo alcance, que desde 1983 investe na complementação educacional de meninos e meninas carentes de idades entre 7 e 14 anos, em diversos municípios de nove estados brasileiros. Promove atividades esportivas, artísticas, recreativas, além de ministrar noções de saúde e higiene. Elas fazem parte de corais, orquestras, bandas marciais; participam de atividades recreativas, esportivas; integram grupos de danças folclóricas e têm aulas de capoeira, maculelê, artesanato, artes circenses e de cultura popular. (PETROBRÁS, 2006).

Com idade compreendida entre 6 e 15 anos e moradoras da cidade de Mauá, a $22 \mathrm{~km}$ da capital paulista, as crianças atendidas por esse projeto são de baixa renda e algumas indicadas pelo Conselho Tutelar. Tal projeto teve a participação de dois professores e um estagiário de Educação Física, e atendeu a 230 crianças inscritas (100, no período matutino, e 130, no vespertino).

As aulas foram ministradas da seguinte maneira: os educandos foram divididos em "iniciantes" (com idade entre 6 e 10 anos) e "intermediários" (entre 11 e 15 anos). As aulas tinham a duração de 1 hora e 10 minutos e eram realizadas duas vezes por semana. O projeto iniciou-se nessa cidade a partir de fevereiro, mas as atividades circenses foram aplicadas de agosto a dezembro, por questões burocráticas e pela necessidade de contemplar outros conteúdos da Educação Física.

A dificuldade de incorporar as atividades circenses ao programa indica uma antiga discriminação vivida pelo circo, a de que esta prática é uma diversão descomprometida "que não pretendia educar, apenas encantar" (SOARES, 2002, p. 55). 
Notou-se que as crianças participantes do projeto questionavam sob forma de gracejos e zombarias - o fato de aprender as atividades circenses. Esse discurso pejorativo com relação às práticas circenses era comum entre crianças.

No entanto, com o envolvimento das crianças no projeto, essa discriminação, aparentemente, diminui, pois elas encontraram nessas atividades possibilidades de uma forma de trabalho, cooperação, educação, elevação da autoestima, aceitação (inclusão), respeito, prazer, diversão, solidariedade.

Os espaços

Os espaços disponíveis para a execução das aulas de Educação Física, em específico para o desenvolvimento das atividades circenses, possuem formatos diferenciados e, conforme suas características, "os educandos vão desenvolver as tarefas propostas pelo educador com maior ou menor eficiência e segurança" (BORTOLETO, 2003, p. 130); esta realidade foi constada na experiência que estamos relatando.

Todas as modalidades, segundo o relato do professor, foram vivenciadas nos espaços oferecidos pela empresa promotora do projeto. Algumas diferenças no processo de ensino-aprendizagem ocorreram, pois houve modalidades circenses mais ou menos apropriadas aos espaços disponíveis.

Para melhor compreensão, vale recapitular a reflexão sobre os espaços mais ou menos adequados para a prática circense feita por Bortoleto e Carvalho (2003, p. 60) quando mencionam existir "espaços controlados ou estáveis", cuja adequação é alta, e "espaços não controlados ou instáveis", pouco recomendados. Atendendo a estas indicações, é possível dizer que os espaços em questão são estáveis e instáveis. O primeiro deles, uma quadra esportiva de cimento plana, mas de uso restrito, pouco recomendável em dias muito ensolarados ou chuvosos, devido à ausência de teto. O segundo espaço, o "gramadão", repleto de irregularidades e onde, em dia de chuva, torna-se um lamaçal escorregadio, o que dificulta a realização das atividades. $\mathrm{O}$ terceiro espaço, uma sala pequena, pode ser considerado estável e sua única limitação está em seu tamanho e altura, que impedem grandes movimentos ou saltos. Apesar das restrições apresentadas, o desenvolvimento das atividades foi relativamente normal respeitando o progra- 
ma inicial do projeto.

Programação das aulas

As aulas foram organizadas de forma a propiciar a manipulação e conhecimento dos objetos, acentuando a curiosidade e descoberta das crianças.

Havia um número elevado de crianças em proporção ao tempo disponível, quantidade de material destinado às aulas e o número de modalidades ensinadas. $\mathrm{Na}$ tentativa de amenizar possíveis empecilhos, a cada aula, se inseriam novos objetos e atividades circenses, e todos passavam por todas as atividades como se fosse um "circuito", o que proporcionava a oportunidade de experimentação de todas as atividades selecionadas: malabares (clave, swing pool, bola de contato, aro, diabolô, bolinhas, bastão chinês), equilíbrio sobre o objeto (pé de lata, corda bamba e rola bola), equilíbrio de objetos (prato de equilíbrio), acrobacias (força e equilíbrio, solo), interpretação (palhaços) e outras (mágicas).

No primeiro dia de aula, os educandos conheceram uma dessas modalidades e foram divididos em dois grupos: grupo de execução e grupo de ajuda. No decorrer da aula, os grupos trocavam de posto: o de ajuda passa à execução e vice-versa.

$\mathrm{Na}$ segunda aula, apresentou-se outra modalidade e a turma foi novamente dividida em dois grupos: um para cada modalidade. Os grupos foram subdivididos em grupo de execução e grupo de ajuda, um retomava a modalidade já aprendida, o outro experimentava a modalidade nova. Após um tempo, os materiais e funções eram trocados.

$\mathrm{Na}$ terceira aula, mais uma modalidade foi ensinada e os educandos divididos em três grupos: uma para cada modalidade, sendo cada um deles subdividido novamente em grupo de execução e grupo de ajuda. Um grupo retornava às modalidades aprendidas na aula anterior e o outro experimentava a nova modalidade. Desta forma, esse processo ocorreu sucessivamente, aula após aula, até que todas as modalidades selecionadas fossem ensinadas. Esta foi a estratégia adotada para o contato dos alunos com tantas modalidades circense em tão pouco tempo e recurso.

As aulas 
Conforme mencionado, os encontros com os educandos tinham duração de 1 hora e 10 minutos, e aconteciam duas vezes por semana. Como o processo de ensino-aprendizagem "deve seguir uma progressão lógica e suficientemente flexível para que os praticantes possam adquirir os conhecimentos de forma segura e constante" (BORTOLETO, 2004, p. 102), cada uma destas aulas foi dividida em quatro momentos, descritos a seguir.

I) No primeiro momento, o educador responsável apresentava o material a ser utilizado na aula, relatava um pouco de sua história, explicava princípios fundamentais do seu manuseio, e, em seguida, demonstrava alguns truques, passíveis de serem executados.

II) No segundo momento, os educandos tinham a possibilidade de realizar os truques, utilizando a divisão do grupo já relatada. Os truques lhes foram ensinados, por etapas, respeitando o processo de ensinoaprendizagem, ou seja, o educador demonstrava apenas uma manobra e os educandos a executavam em seguida. Após a assimilação desta, ele acrescentava outra sucessivamente, até que todas elas fossem inseridas nesse processo e que os alunos aprendessem o movimento completo de cada elemento circense.

O interessante desse processo foi a escassez do material. Esta situação ocasionou momentos de companheirismo entre educandos (intercâmbio de material, respeito às diferenças, cooperação), dando um caráter coletivo às atividades, conforme mencionam Bortoleto e Machado (2003 p. 67).

No caso dessa experiência e com a falta de materiais, o professor coordenou a aula da seguinte maneira: os alunos eram divididos em grupo e, enquanto o primeiro deles começava a executar as atividades, o segundo acompanhava a execução e fornecia o retorno aos colegas, quando necessário, e vice-versa. No decorrer das aulas, aqueles mais habilidosos ajudavam os colegas que apresentavam maiores dificuldades.

III) No terceiro momento, quando os educandos já conheciam os elementos circenses podiam experimentar outras possibilidades de execução criadas por eles mesmos (criação e exploração).

IV) E, no quarto momento, o dos "renegados"2, não havia uma frequência programada e tudo acontecia respeitando a motivação da aula. O educador desafiava os educandos a apresentar-se diante de todos os colegas de classe. A proposta foi tão aceita que essa atividade, "os renegados", começou a surgir entre os próprios educandos, pois se

2-Renegados - termo utilizado para estimular a apresentação de alguma modalidade circense. 
mostrava um espaço de desafio em que se podia trabalhar com a imaginação e pensar na "possibilidade" de serem artistas circenses. Nesta fase, também existia um momento no qual os alunos podiam escolher livremente um material para manipular.

A análise das modalidades ministradas

Percebemos que as modalidades circenses ensinadas neste projeto foram selecionadas de acordo com a possibilidade de: material disponível, sobretudo, alternativo que foi confeccionado pelo educador e educandos; espaços disponíveis (gramadão, sala pequena e quadra poliesportiva) e adequados à realização das modalidades ; e a faixa etária pertinente ao aprendizado das modalidades.

\begin{tabular}{|c|c|c|c|c|}
\hline \multirow[b]{2}{*}{ Modalidade } & \multicolumn{4}{|c|}{ Idade } \\
\hline & 7 a 8 anos & 9 a 10 anos & $\begin{array}{c}11 \text { a } 12 \\
\text { anos }\end{array}$ & $\begin{array}{c}13 \text { a } 14 \\
\text { anos }\end{array}$ \\
\hline \multicolumn{5}{|l|}{ Aro } \\
\hline \multicolumn{5}{|c|}{ Acrobacia: coletiva $e$ individual } \\
\hline \multicolumn{5}{|l|}{ Bolinhas } \\
\hline Bola de contato & * & & & \\
\hline Chve & * & \pm & & \\
\hline \multicolumn{5}{|l|}{ Clown ou palhaço } \\
\hline Dinbolô & * & & & \\
\hline \multicolumn{5}{|c|}{ Devil stick ou bastão cluinês } \\
\hline Prato cluinês & & & * & * \\
\hline \multicolumn{5}{|l|}{ Perna de pau } \\
\hline \multicolumn{5}{|l|}{ Poi-poi ou carioca } \\
\hline Roha-roha & & & & \\
\hline
\end{tabular}

Observação: As células destacadas em preto se referem a modalidades que não foram aplicadas nas respectivas faixas etárias

Quadro 1: Análise das modalidades circenses

Durante as aulas, o educador e seus colaboradores foram identificando, registrando as dificuldades e facilidades no desenvolvimento de cada modalidade circense, o que reorientou a programação das atividades. A partir destas observações e registros, construímos os quadros que seguem abaixo com sugestões de confecção de material alternativo ou adaptado. 


\begin{tabular}{|c|c|c|}
\hline MODALIDADES & $\begin{array}{c}\text { POSSIBILIDADE DE } \\
\text { CONSTRUCĈ̃O DE MATERIAL } \\
\text { ALTERNATIVO }\end{array}$ & $\begin{array}{c}\text { ESPACOS } \\
\text { MAIS RECOMENDADOS }\end{array}$ \\
\hline \multicolumn{3}{|c|}{ 1. MALABARES } \\
\hline Clave & Sim & Quadra \\
\hline Swing pol & Sim & Sala pequena \\
\hline Boh de contato & Năo & Sala pequena \\
\hline Aro & Sim & Quadra \\
\hline Diabolô & Năo & Quadra \\
\hline Bolinhas & Sim & Quadra \\
\hline Devil stick ou Bastão chinês & Sim & Quadra \\
\hline \multicolumn{3}{|c|}{ 2. EQUILIBRIO SOBRE OBJETO } \\
\hline Pé de lata & Sim & Quadra \\
\hline Roh-boh & Sim & Quadra \\
\hline Corda bamba & Năo & Gramadäo \\
\hline \multicolumn{3}{|c|}{ 3. EQUILİBRIO DE OBJETOS } \\
\hline Prato de equilibrio & Sim & Sala pequena \\
\hline \multicolumn{3}{|c|}{ 4. ACROBACIA } \\
\hline $\begin{array}{l}\text { Acrobacia coletiva: Equilibrios e } \\
\text { forca }\end{array}$ & Não necessita & Gramadäo \\
\hline Acrobacias de solo & Não & Gramadäo \\
\hline \multicolumn{3}{|c|}{ 5. PALHACCOSINTERPRETAÇAO } \\
\hline Clown ou Palhaço & Sim & Sala pequena \\
\hline \multicolumn{3}{|c|}{ 6. OUTRAS } \\
\hline Mágicas & Sim & Sala pequena \\
\hline
\end{tabular}

Quadro 2: Análise das modalidades circenses

\begin{tabular}{|c|c|c|c|c|}
\hline MODALIDADES & DE SCRIÇÄO & $\begin{array}{c}\text { MATERIAL } \\
\text { ALTERNATIVO }\end{array}$ & \multicolumn{2}{|c|}{$\begin{array}{c}\text { APLICACCAO } \\
\text { DIFICULDADES E FACILIDADES }\end{array}$} \\
\hline \multicolumn{5}{|c|}{ 1. MALABARES - PART I } \\
\hline Swing pool & $\begin{array}{l}\text { Sä̀ parecidos com } \\
\text { cometas, e têm uma bola, } \\
\text { a qual sustenta uma calda } \\
\text { que é pendurada por um } \\
\text { barbante que permite o } \\
\text { movimento das } \\
\text { manobras. }\end{array}$ & $\begin{array}{l}\text { - jomal; } \\
\text { - papel crepom; } \\
\text { - barbante; } \\
\text { - tecido. }\end{array}$ & $\begin{array}{lr}\text { Não apresenta } \\
\text { dificuldades de } \\
\text { ervino } \\
\text { aprendizagem }\end{array}$ & $\begin{array}{l}\text { E um aparellho fácil } \\
\text { de ensinar, partindo } \\
\text { de rotaçōes e } \\
\text { cincunduçöes. } \\
\text { Começa-se com um } \\
\text { objeto, passando } \\
\text { depois a dois. }\end{array}$ \\
\hline Boh de Contato & $\begin{array}{l}\text { O objetivo da atividade é } \\
\text { fazer a bola "passear" } \\
\text { pelo corpo, sem perder o } \\
\text { contato com ele. A bola } \\
\text { tem em entre } 100 \mathrm{~m} \text { e } \\
120 \mathrm{~m} \text { e deve ser rigida. }\end{array}$ & $\begin{array}{l}\text { m material altenuativo } \\
\text { seriam bolas de leite de } \\
\text { queimadas. A confecçäo } \\
\text { de bolas de meia ou de } \\
\text { autro material rüo é } \\
\text { recomendada, pois a bola } \\
\text { antesanal apresenta } \\
\text { imperfeiçöes o que } \\
\text { prejudicaria } \\
\text { manupulaçăo. }\end{array}$ & $\begin{array}{l}\text { A maior dificuldade } \\
\text { encontrada é a de } \\
\text { conseguir equilibrar } \\
\text { a bola no corpo. }\end{array}$ & $\begin{array}{l}\text { A execuçäo das } \\
\text { manobras básicas }\end{array}$ \\
\hline Aro & $\begin{array}{l}\text { Também conhecido como } \\
\text { argola. Equipamento de } \\
\text { malabares de formato } \\
\text { redondo (12 polegadas), } \\
\text { com um orificio no meio } \\
\text { (BORTOLETO, 2008) }\end{array}$ & $\begin{array}{l}\text { - papeläo (duas tiras de } \\
\text { papeläo; errolá-las au } \\
\text { fita crepe); }\end{array}$ & $\begin{array}{l}\text { A dificuldade do } \\
\text { aro é no começo, é } \\
\text { o lançamento, pois } \\
\text { ele tem facilidade } \\
\text { de oscilar nuito, } \\
\text { principalennntre } \\
\text { com manifestaçöes } \\
\text { da natureza, como o } \\
\text { vento. } \\
\end{array}$ & $\begin{array}{l}\text { A facilidade é a de } \\
\text { segurá-lo, devido à } \\
\text { grande superficie } \\
\text { disponivel para tal } \\
\text { açäo. }\end{array}$ \\
\hline Diabolo & $\begin{array}{l}\text { Equipamentos que mais } \\
\text { se parece com duas taças } \\
\text { encaixadas uma na outra, } \\
\text { é usado com uma } \\
\text { cordinha com dois } \\
\text { bastöezinhos na ponta. }\end{array}$ & $\begin{array}{l}\text { A construção artesanal é } \\
\text { dificil e pouco } \\
\text { recomendada. }\end{array}$ & $\begin{array}{l}\text { A dificuldade é a } \\
\text { transiçäo entre o } \\
\text { momento ou que } \\
\text { diabolô começa a } \\
\text { desequilibrar-se e o } \\
\text { de ter que jogá-lo } \\
\text { para a alto. Com } \\
\text { crianças pequenas, a } \\
\text { corvda deve ser } \\
\text { diminuida } \\
\text { (ajustada). }\end{array}$ & $\begin{array}{l}\text { Seu maruseio é } \\
\text { simples, as crianças } \\
\text { näo apresentam } \\
\text { dificuldades de } \\
\text { manobrá-lo, is to é, de } \\
\text { fazê-lo pegar } \\
\text { velocidade e rolar } \\
\text { pela cordinha }\end{array}$ \\
\hline
\end{tabular}

Quadro 3: Modalidades escolhidas e suas particularidades no projeto 


\begin{tabular}{|c|c|c|c|c|}
\hline MODALIDADE S & DE SCRIÇÄO & $\begin{array}{c}\text { MATERIAL } \\
\text { ALTERNATIVO }\end{array}$ & \multicolumn{2}{|c|}{$\begin{array}{c}\text { APLICACCAO } \\
\text { DIFICULDADES E FACILIDADES }\end{array}$} \\
\hline \multicolumn{5}{|c|}{ 1. MALABARES -PART II } \\
\hline Bohneas & $\begin{array}{l}\text { Podem ser distintos o seu } \\
\text { material ou tamanho: de } \\
\text { silicone, de bexiga ou de } \\
\text { painço. }\end{array}$ & $\begin{array}{l}\text { - bexiga; } \\
\text { - painço; } \\
\text { - saco plástico. }\end{array}$ & $\begin{array}{l}\text { De irício o } \\
\text { desconhecimento do } \\
\text { material é uma } \\
\text { dificuldade, } \\
\text { rapidamente } \\
\text { contomada. }\end{array}$ & $\begin{array}{l}\text { A manipulaçäo é } \\
\text { fäcil e nuitas } \\
\text { crianças possuem } \\
\text { habilidades } \\
\text { adiquinidas na } \\
\text { infância através de } \\
\text { jogos como } \\
\text { queimada. }\end{array}$ \\
\hline $\begin{array}{l}\text { Devil stick oubastäo } \\
\text { clünês }\end{array}$ & $\begin{array}{l}\text { Consiste em três bastöes, } \\
\text { um maior e mais grosso, e } \\
\text { outros dois, menores e } \\
\text { mais finos. }\end{array}$ & $\begin{array}{l}\text { - Cabo de vassoura; } \\
\text { - câmara de ar de pneu } \\
\text { de bicicleta; } \\
\text { - cola quente }\end{array}$ & $\begin{array}{l}\text { A dificuldade é } \\
\text { dominar o material } \\
\text { sem a flor na ponta, } \\
\text { porque ele fica mais } \\
\text { rápido. }\end{array}$ & $\begin{array}{l}\text { E material de fácil } \\
\text { aprendizagem. }\end{array}$ \\
\hline
\end{tabular}

Quadro 4: Modalidades escolhidas e suas particularidades no projeto

\begin{tabular}{|c|c|c|c|c|}
\hline MODALIDADE S & DE SCRIC̣ÄO & $\begin{array}{c}\text { MATERIAL } \\
\text { ALTERNATIVO }\end{array}$ & \multicolumn{2}{|c|}{$\begin{array}{c}\text { APLICACCAO } \\
\text { DIFICULDADE S E FACILIDADES }\end{array}$} \\
\hline \multicolumn{5}{|c|}{ 2. ACROBACIA } \\
\hline $\begin{array}{c}\text { Equilhbrios corporais } \\
\text { (individual e em } \\
\text { duph) }\end{array}$ & $\begin{array}{l}\text { Traballha a força, além de } \\
\text { cooperaçä́o, confiança e } \\
\text { respeito. }\end{array}$ & Näo utiliza material. & $\begin{array}{l}\text { A dificuldade foi o } \\
\text { numero elevado de } \\
\text { crianças }\end{array}$ & $\begin{array}{l}\text { A cooperaçäo entre } \\
\text { os colegas; e a } \\
\text { inclusäo dos } \\
\text { "gordinhos" que } \\
\text { são solicitados para } \\
\text { compor as figuras. }\end{array}$ \\
\hline Acrobacias de solo & $\begin{array}{l}\text { Acrobacias simples de } \\
\text { solo (rolamento, etc.) }\end{array}$ & É necessánio colchöes. & $\begin{array}{l}\text { Os ahunos tiveram } \\
\text { certas dificuldades nas } \\
\text { atividades de inversäo. } \\
\text { Outra dificuldade foi a } \\
\text { de ter de usar } \\
\text { equipamento de } \\
\text { segurança quando os } \\
\text { ahunos tinham que } \\
\text { subir acima de um } \\
\text { metro de altura. }\end{array}$ & $\begin{array}{l}\text { Estinula } \\
\text { cooperaçäo durante } \\
\text { as ajudas da } \\
\text { execuçäo. Näo } \\
\text { requer materiais } \\
\text { complexos }\end{array}$ \\
\hline
\end{tabular}

Quadro 5: Modalidades escolhidas e suas particularidades no projeto

O acompanhamento das aulas

No acompanhamento das aulas observou-se, em relação aos educandos, a motivação, inclusão e respeito à diversidade de cada um, como é recomendado pelos princípios do PCNs (BRASIL, 1996) (Inclusão, Diversidade e Conteúdo), pois as atividades circenses possibilitam a relação entre as dimensões cognitiva, física, afetiva e social, uma vez que as características físicas dos educandos não influenciam na execução de diferentes modalidades que a arte circense oferece. 
Todos os relatórios construídos pelos professores e o estagiário sobre o projeto estão em posse da Petrobrás. O acompanhamento das atividades relatadas foi realizado por meio de registros fotográficos, relatórios semanais, observação de cada aula do professor. A avaliação e o acompanhamento constante dos educandos fez o educador levantar informações relevantes quanto à adequação das modalidades circenses à faixa etária dos educandos envolvidos.

Espetáculo de encerramento: montagem e apresentação

O espetáculo foi uma das formas avaliativas encontradas para demonstrar as competências adquiridas pelos educandos durante o projeto - Programa de Criança. A participação de quase a totalidade das crianças atendidas e a autonomia delas foram fatores relevantes, no qual afirmamos o fascínio que o projeto inculcou nas crianças.

Tal apresentação foi elaborada dentro de um tema determinado pelo educador e teve o nome de Alegria, no qual cada educando pôde escolher o material que gostaria de apresentar; grupos foram compostos por afinidade entre os participantes e entre estes e o aparelho escolhido: cada grupo ficou responsável pela apresentação do número composto por uma ou mais atividades circenses aprendidas.

O espaço disponibilizado para a apresentação final do projeto foi o refeitório dos funcionários da Petrobrás, situado na própria empresa, em torno das $12 \mathrm{~h}$ para que as crianças pudessem socializar o que tinham apreendido e os funcionários contemplar o desempenho das crianças nas atividades circenses.

A avaliação das aulas

Uma avaliação processual e constante dentro do projeto - esta ocorreu semanalmente, quando os professores registravam as aulas e discutiam as modificações positivas ou negativas ocorridas durante estas - foi fundamental não só para qualificar o ensino-aprendizado de educandos e educadores como também para ajustar os erros e acertos detectados no processo, conforme recomenda a seguinte citação: "o entendimento da avaliação não somente na perspectiva da aprendizagem, mas também do ensino, levando-se em conta que uma das funções da mesma é informar e orientar para a melhoria do processo ensino-aprendizagem" (COLETIVO, 1992, p. 105). 
Outro ponto importante levado em conta pelo educador, no momento da avaliação, foi a preocupação constante com o respeito à individualidade dos educandos no momento de escolherem, para apresentação no espetáculo circense, os aparelhos com os quais tivessem mais afinidade, pois "a compreensão de uma criança na pré-escola, não é a mesma que está na quarta série, nem da que freqüenta a oitava" (COLETIVO, p. 33,1992) com isso a adequação e a liberdade de escolha do que mais se identifica é fator relevante para uma avaliação significativa.

Outras peculiaridades do projeto

Alguns fatos evidentes ocorridos no Projeto foram que alguns alunos que se sentiam excluídos conseguiram se identificar com a proposta, como foi o caso do educando Gabriel . Com 10 anos de idade, e $95 \mathrm{~kg}$, sentia pavor em relação às aulas de Educação Física, mas encontrou na modalidade de acrobacia um espaço em que poderia desempenhar o melhor dos seus papéis: o apoio das pirâmides, isto é, elevava nos ombros as crianças que deveriam realizar os movimentos acrobáticos.

Houve também o caso da aluna Maria, que se sentia excluída por ser tímida e calada, entretanto encontrou na atividade de malabares (jogar as bolinhas) um espaço de destaque entre os colegas. Aliás, a cooperação entre as crianças, ampliou a solidariedade entre elas nos momentos coletivos, criando laços como de uma grande família.

Cabe destacar, ainda, que a competitividade nas atividades circenses mostrou-se uma grande aliada para a apreensão de novos movimentos com os objetos, permitindo a superação e a criação de novas formas de manipulação e expressão corporal.

\section{Considerações finais}

Este artigo traz considerações que julgamos importantes sobre a funcionalidade e a aplicabilidade das atividades circenses dentro do contexto educativo (formal e não formal) e recreativo. Evidencia o grande desenvolvimento afetivo-cognitivo, social e cultural proporcionado pelo Circo, quando é tratado de modo adequado (DUPRAT; BORTOLETO, 2007 , p. 174).

Considerando alguns resultados do Projeto Criança, os responsá- 
veis por ele destacaram que houve a mudança de postura, de comportamento, cooperação entre os pares, elevação de autoestima e uma das observações feitas pela equipe da Petrobrás foi a de não haver uma criança em destaque, mas todas, permitindo que houvesse soluções conscientes para os conflitos.

Além disso, o Projeto Criança permitiu construções significativas em outros projetos na Comunidade do Jardim Oratório e escolas públicas em Ribeirão Pires.

Pensar as atividades circenses nos termos supramencionados é possibilitar a inclusão dos excluídos, respeitando a diversidade existente no Brasil, na busca de uma educação de qualidade incitando a criatividade e autonomia por meio do movimento corporal e suas reflexões. É considerar novos autores que possam escrever suas próprias histórias e perpetuar suas experiências para legitimar uma arte fascinante e reveladora de inúmeras possibilidades, seja em âmbito formal ou não-formal.

Além das facilidades de inserção da arte circense nos conteúdos das aulas de Educação Física, "cabe ressaltar que em todos os âmbitos de atuação o profissional de educação física deve estar preocupado com a formação humana capacitando seus alunos numa ampla esfera de conhecimento" (DUPRAT; BORTOLETO, 2007, p.177), desta forma o circo se torna um excelente conteúdo para ser ensinado.

\section{Perspectivas}

O circo que percorre o mundo com seus encantos e fascínio há séculos passou por momentos de esplendor e difamação. Hoje, embora para muitos tenha perdido o significado de fonte de renda e sobrevivência, desponta em novos formatos. É o caso do circo escola que ganha mais adeptos entre educandos e educadores.

Outra ação estimulada na pesquisa desse tema foi a possibilidade e a facilidade de criar mais um canto lúdico na brinquedoteca, denominado Canto do Circo, local onde as crianças poderiam explorar as modalidades circenses e, futuramente, interessar-se por esta arte.

Finalmente, entendemos que este artigo vem somar-se com a proposta de Duprat e Bortoleto (2007, p. 176), Baroni (2006) e Bortoleto et al (2008), quando afirmam que a atividade circense requer uma pedagogia própria, ou ao menos preocupada com suas particularidades. Todo um desafio aos professores de Educação Física que abrimos essa 
oportunidade. Assim, com este registro, esperamos contribuir para a pedagogia da arte circense na Educação Física escolar formal.

Opening the doors: for the circus activities in the pertaining to school physical education: an experience

\begin{abstract}
In this study, we show the experience in developing circus activities during Physical Education extracurricular lessons in a social project sponsored by the tax-incentive law, in the municipality of Mauá (State of São Paulo) during 2006. We describe, thus, how important is such sort of activity for the Physical Education lessons. It is also included here how we used the circus events, educational process, and suchlike.
\end{abstract}

Keywords: Circus Activities - School Physical Education - Circus

Abriendo las puertas para las actividades circenses en la educación física escolar: un relato de la experiencia

\title{
Resumen
}

Este artículo describe la experiencia del desarrollo de las actividades del circo en las clases extra-curriculares de educación física, en un proyecto social patrocinado por la ley de los incentivos fiscales, en la ciudad de Mauá (SP) durante el año de 2006. En él describimos la importancia de este tipo de actividad para las clases de educación física; las modalidades del circo enseñadas, el proceso pedagógico empleado y otros aspectos del proyecto.

Palabras clave: Actividades Circenses - Educación Física Escolar - Circo

\section{Referências}

BARONI, J. F. Arte circense: a magia e/o encantamento dentro e fora das lonas. Pensar a Prática, Goiânia, v. 9, n. 1, p.81-99, 2006.

BORTOLETO, M A. C. et al. Introdução à pedagogia das atividades circenses. Jundiaí: Fontoura, 2008.

BORTOleto, M. A. C. . Rola-bola: iniciação. Revista Movimento \& Percepção, Espírito Santo de Pinhal. v. 4, n. 4-5, p. 100-109, jan./dez., 2004.

BORTOLETO, M. A.; MACHADO, G. de A. Reflexões sobre o circo e a Educação Física. Corpo-consciência, Santo André, n. 12, p. 3969, 2003.

BRASIL, Ministério da Educação. Secretaria de Ensino Fundamental. Parâmetros curriculares nacionais de Educação Física. Brasília: 
MEC/SEF, 1997.

BRASIL. Lei de diretrizes e bases da Educação Nacional: Lei n. 9394/96, de 20 de dezembro de 1996. Brasília: MEC, 1996.

COLETIVO DE AUTORES. Metodologia do ensino de Educação Física. São Paulo: Cortez, 1992.

DENCKER, A. de F. M. Métodos e técnicas de pesquisa em turismo. 8. ed. São Paulo: Futura, 1998.

DUPRAT, R. M.; BORTOLETO, M. A. C. Educação Física escolar: pedagogia e didática das atividades circenses. Revista Brasileira de Ciência do Esporte , v. 28, p.171-189, jan. 2007.

SCHWARTZ, G. M. Emoção, aventura e risco - a dinâmica metafórica dos novos estilos. In: BURGOS, M. S.; PINTO, L. M. S. (Org.). Lazer e estilo de vida. 1. ed. Santa Cruz do Sul: EDUNISA, 2002. p.104.

SILVA, E. O circo: sua arte e seus saberes. O circo no Brasil do final do século XIX a meados do XX. 1996, 172 f. Dissertação (Mestrado em História) - Instituto de Filosofia e Ciências Humanas, Unicamp, Campinas, 1996.

SOARES, C. Imagens da educação no corpo. 2. ed. rev. Campinas, SP: Autores Associados, 2002.

Recebido em: 21/07/2009

Revisado em: 24/01/2010

Aprovado em: 02/03/2010

Endereço para correspondência

bortoleto@fef.unicamp.br

Marco Antonio Coelho Bortoleto

Universidade Estadual de Campinas, Faculdade de Educação Física

Rua: Érico Veríssimo

Barão Geraldo - Cid. Univ.

13083-970 - Campinas, SP - Brasil - Caixa-Postal: 6134 